\author{
Military Technical College \\ Kobry El-Kobbah, \\ Cairo, Egypt.
}

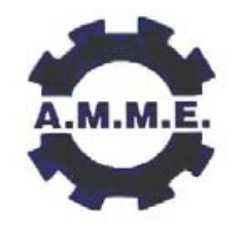

\title{
IMPROVEMENT OF FATIGUE LIFE BY REDUCING THE FORMATION OF CRACK DURING EDM PROCESS
}

\author{
TAI $^{*}$ T.-Y., LEE ${ }^{* *}$ H.-T. and HSU*** F.-C.
}

\begin{abstract}
The present study performs an experimental investigation to identify the EDM processing parameters which suppress the formation of surface cracks in the machined surface of SKD11 tool steel specimens. The rapid heating and cooling effects inherent in the electro-discharge machining (EDM) process result in the formation of a brittle recast layer on the machined surface. This layer increases the surface roughness of the machined component and is characterized by globules of debris, shallow craters, pockmarks, voids and cracks.
\end{abstract}

In the EDM trials, the specimens are machined using pulse currents of 4A, 16A or $32 \mathrm{~A}$ with pulse-on durations of either $4 \mu \mathrm{s}$ or $16 \mu \mathrm{s}$. The various specimens are then fatigue tested at loads ranging from $150 \sim 245 \mathrm{Kg}$ in order to determine their respective fatigue lives. A polished SKD11 specimen is also fatigue tested for comparison purposes. The results show that the EDM processing parameters have a significant effect on the surface cracking characteristics. Specifically, when the EDM process is performed using a pulse current of $4 \mathrm{~A}$ and a pulse-on duration of $16 \mu \mathrm{s}$, the machined surface is found to have a high surface crack density and some of the cracks penetrate as far as the parent material. With processing parameters of $16 \mathrm{~A} / 4 \mu \mathrm{s}$ and $32 \mathrm{~A} / 16 \mu \mathrm{s}$, a recast layer is formed on the surface of the machined specimen, but no surface cracks are observed. Hence, it can be inferred that increasing the pulse current and reducing the pulse-on duration provides an effective means of suppressing the surface cracking phenomenon. Higher values of

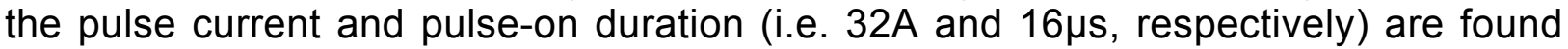
to increase the average thickness of the recast layer and to prompt a corresponding reduction in the fatigue life of the machined specimen.

\section{KEY WORDS}

Electro-discharge Machining (EDM), Fatigue Life, Surface Crack.

\footnotetext{
* Assistant professor, Dpt. of Mechanical Engineering, Southern Taiwan University, Tainan, Taiwan.

** Professor, Dpt. of Mechanical Engineering, National Cheng-Kung University, Tainan, Taiwan.

*** Engineer, Metal Industries Research \& Development Centre (MIRDC), Kaohsiung, Taiwan.
} 


\section{INTRODUCTION}

Technological advances have led to an increasing use of high strength, high hardness materials in manufacturing industries. In the machining of these materials, traditional manufacturing processes are increasingly being replaced by more advanced techniques such as electro-discharge machining (EDM), ultrasonic machining(USM), electric chemical machining(ECM) and laser machining. Consequently, EDM has emerged as the method of choice for the fabrication of high-precision dies and cutting tools and for the production of delicate, high-strength components such as those used throughout the aerospace industry, for example [1,2].

EDM may be used to machine any conductive material. A further advantage of EDM is that there is no direct contact between the electrode and the component during machining, and therefore no deformation occurs, even for thin components. However, due to the rapid heating and cooling effects induced by the machining process, a thermally recast layer will form on the surface of the component. The characteristics of the recast layer are closely related to the phase transformation which takes place during the solidification process. The depth and size of the cracks formed on the recast layer increase as the heat energy per spark increases. The majority of these cracks terminate within the recast layer or at the interface between the recast layer and the workpiece. Many researchers have shown that this leads to a significant reduction in the strength, corrosion resistance and wear resistance of the machined component [3]. EDM'd components are commonly applied in high-temperature, high-stress, and highfatigue-load environments. Under such conditions, the cracks on the machined surface act as stress raisers and lead to a considerable reduction in the fatigue life of the component.

Zeid [4] examined the influence of the EDM pulse current and pulse-on duration parameters on the fatigue life of AISI D6 tool steel. The results showed that the fatigue life was correlated to the thickness of the white layer and to the presence of surface cracks. Ramulu et al. [5] investigated the correlation between the EDM'd surface characteristics and the fatigue strength of A356 aluminum alloy with $15 \mathrm{Vol} \%$ $\mathrm{SiC}$ addition. The experimental results revealed that the micro-cracks and shallow craters on the machined surface resulted in severe crack propagation during fatigue loading. Guu and Hocheng [6] attempted to improve the fatigue life of EDM'd AISI D2 tool steel by sputtering a TiN layer with a thickness of $3 \mu \mathrm{m}$ onto the machined surface using a physical vapor deposition (PVD) process. It was shown that TiN layer yielded a significant improvement in the fatigue life of the workpiece.

As described above, researchers have proposed improving the fatigue life of EDM'd component by using a post-machining operation to remove the recast layer or to coat the machined surface with a metallic layer. However, both methods inevitably extend the manufacturing time and increase the manufacturing cost. Accordingly, the current study conducts an experimental investigation to identify the optimal EDM machining parameters which suppress the formation of cracks.

\section{EXPERIMENTAL PROCEDURE}

In the current study, the machining tests were performed using a copper electrode with a diameter of $6.4 \mathrm{~mm}$ and a kerosene dielectric fluid. The subject material is 
SKD11. The EDM parameters which have the most significant effect upon the quality of the EDM process are pulse voltage, pulse current, pulse-on duration(ON-time), and pulse-off duration(OFF-time). For this reason, this study establishes its full factorial design to observe the surface integrity of machined surface. The following values of pulse current are used: $4 \mathrm{~A}, 6 \mathrm{~A}, 8 \mathrm{~A}, 12 \mathrm{~A}$ and $16 \mathrm{~A}$, with pulse-on times of $6 \mu \mathrm{s}, 9 \mu \mathrm{s}, 12 \mu \mathrm{s}$ and $16 \mu \mathrm{s}$. The pulse voltage is maintained at a constant $200 \mathrm{~V}$. The duty factor is fixed to 0.5 .

Then three pulse current / pulse-on duration settings were considered to perform fatigue test, namely 4A / $16 \mu \mathrm{s}, 16 \mathrm{~A} / 4 \mu \mathrm{s}$ and 32A / $16 \mu \mathrm{s}$, respectively. A polished SKD11 specimen is also fatigue tested for comparison purposes. Fatigue tests were then performed at maximum loads ranging from $150 \mathrm{Kg}$ to $245 \mathrm{Kg}$ to establish the fatigue life of the various specimens. The size of fatigue specimen is reveals in Figure 1.

\section{RESULTS}

\section{Surface Morphology}

The distinctive morphology of a surface which has undergone EDM machining, is due to the enormous amount of heat generated by the discharges, which causes melting and vaporization of the material, followed by rapid cooling. The surface profile presented in Figure 2 reveals that the surface roughness is caused by an uneven fusing structure, globules of debris, shallow craters, pockmarks, voids and cracks. These effects become more pronounced as the pulse current and pulse-on duration increase.

\section{Crack}

Observation of the machined surface, and the sample sections, reveals that the surface cracks are often micro-cracks. The high multiple microscope shows that cracks exist in the white layer; initiating at its surface, and traveling down perpendicularly towards the parent material. In the vast majority of cases the cracks terminate within the white layer, or just on the interface of the white layer and the parent material. Only rarely do the cracks penetrate the entire white layer thickness to extend into the parent material as shown in Figure 3.

Since it is not easy to quantify the cracking in terms of an estimation of the width, length, or depth of the crack, or even by the amount of cracking, this study defines a "surface crack density", i.e. the total length of cracks $(\mathrm{cm})$ in a unit area $\left(\mathrm{cm}^{2}\right)$ to evaluate the severity of cracking. Table 1 present an analysis of this measure for SKD11, and shows how the surface crack density varies with changes in pulse-on duration and pulse current.

If the relationship between the cracks and the EDM parameters is considered, it is found that, for a constant pulse current, the surface crack density increases as the pulse-on time increases. On the other hand, if the pulse-on duration is held constant, then the surface crack density decreases as the pulse current increases.

This study of EDM parameters using a full factorial design reveals an interesting phenomenon, namely that there is no absolute relationship between surface crack 
density and pulse energy, i.e. increasing the pulse energy does not automatically lead to increased crack formation. In fact, the maximum crack density actually occurs under the machining conditions of minimum pulse current and maximum pulse-on duration.

Figure 4 presents a map which is based upon the experimental results, and which may be used to predict the appearance of cracking. This map makes it very clear when cracking will occur in the EDM machining of SKD11. The region above the prediction line is the "crack zone", while the region below the line is the "no crack zone". According to this map, EDM parameters with the formation of crack and no formation of crack are determined to perform the following fatigue tests.

\section{Fatigue tests}

Three pulse current / pulse-on duration settings were considered, namely $4 \mathrm{~A} / 16 \mu \mathrm{s}$, $16 \mathrm{~A} / 4 \mu \mathrm{s}$ and $32 \mathrm{~A} / 16 \mu \mathrm{s}$, respectively. Among these parameters, cracks will be formed when $4 \mathrm{~A} / 16 \mu \mathrm{s}$ is selected, and cracks will not be formed when 16A / $4 \mu \mathrm{s}$ and $32 \mathrm{~A} / 16 \mu \mathrm{s}$ are selected.

The rapid heating and cooling effect generates a significant stress within the recast layer during the solidification process. In the event that the magnitude of this stress exceeds the yield stress of the recast layer, micro-cracks are formed on the machined surface. Mamalis et al. [7] and Tai and Lee et al. [8,9] reported that surface crack formation is directly related to the EDM machining parameters. Figures 5,6 and 7 present SEM images of the specimens machined using the three pulse current / pulseon duration parameter settings. It can be seen that there is no absolute relationship between the crack density and the electro-discharge energy. No more cracks are formed under a bigger impulse energy, but the maximum crack density occurs under a small pulse current and a long pulse-on time. As the pulse-on duration increases, the crack not only spreads over the workpiece surface, but also penetrates more deeply into the original material, as shown in Figure 8 . The test specimen which is machined through EDM process is shown in Figure 9.

To evaluate the effect of the micro-cracks on the fatigue lives of the three SKD11 specimens shown in Figures 4 6, fatigue tests were performed using maximum loads of $150 \mathrm{Kg}, 185 \mathrm{Kg}, 215 \mathrm{Kg}$ and $245 \mathrm{Kg}$, respectively, with a stress ratio of $\mathrm{R}=0.1$ and a loading frequency of $10 \mathrm{~Hz}$. Polished (unmachined) SKD11 specimens were also tested under the same conditions for comparison purposes. The corresponding experimental results are summarized in Figure 10. It is apparent that the specimen containing surface cracks (i.e. Specimen 2) has the shortest fatigue life of the four specimens at all values of the test load. In general, when fatigue testing unflawed specimens, the cyclic application of a tensile load results first in crack initiation and then in crack propagation, leading to the eventual failure of the specimen. However in the type 2 specimens considered in the present study, a crack already exists, and thus the application of the cyclic load leads directly to crack propagation. As a result, the presence of surface cracks yields a significant reduction in the fatigue life. From the results presented in Figure 10, it is seen that the tested specimens can be ranked in terms of reducing fatigue life as follows: Specimen 1: polished workpiece, Specimen 2: workpiece with surface cracks, Specimen 3: workpiece with thin white layer and no cracks; Specimen 4: workpiece with thick white layer and no crack. 
Since recast layer's microstructure and chemical composition are significantly different from those of the SKD11 parent material, consequently, a difference in the mechanical properties exists at the interface between the white layer and the parent material. Specifically, the mechanical yield strength, hardness and brittleness properties of the white layer are all greater than those of the parent material. The difference in ductility of the white layer and the parent material has a significant effect on the propagation characteristics of the fatigue crack. When the fatigue crack extends from the white layer, with a relatively high yield strength, to the parent material, with a relatively lower yield strength, its rate of propagation increases. As the white layer thickness increases, its brittleness also increases, and hence cracks are initiated more readily and propagate both more rapidly and more deeply. As a result, an increasing of crack density leads to a significant reduction in the fatigue strength.

\section{CONCLUSION}

1. Increasing the pulse current or reducing the pulse-on duration suppresses the formation of surface cracks in the SKD11 machined surface, and hence improves the fatigue life.

2. The presence of surface cracks leads to a significant reduction in the fatigue life of the machined surface. Under fatigue loads of $245 \mathrm{Kg}, 215 \mathrm{Kg}, 185 \mathrm{Kg}$ and $150 \mathrm{Kg}$, the fatigue life is found to be reduced by around $43 \%, 61 \%, 50 \%$ and $32 \%$, respectively.

3. The specimens considered in the present study can be ranked in terms of reducing fatigue life as follows: (1) the polished specimen, (2) the specimen with a thin recast layer and no surface cracks, (3) the specimen with a thick recast layer and no surface cracks, and (4) the specimen with surface cracks.

\section{ACKNOWLEGEMENT}

The authors gratefully acknowledge the financial support provided to this study by the National Science Council of Taiwan, ROC, under grant number NSC93-2212-E218-011.

\section{REFERENCES}

1. Lee S.H. and Li X.P., "Study of the Surface Integrity of the Machined Workpiece in the EDM of Tungsten Carbide", Journal of Materials Processing Technology, Vol. 139, pp. 315-321, 2003.

2. Jeelani S. and Collins M.R., "Effect of Electric Discharge Machining on the Fatigue Life of Inconel 718", International Journal of Fatigue, Vol. 10, No.2, pp. 121-125, 1988.

3. Yang Y.Y., Fang H.S. and Huang W.G.," A Study on Wear Resistance of the White Layer , "Tribology International, Vol.29, No.5, pp.425-428, 1996.

4. Abu Zeid O.A.,"On the Effect of Electrodischarge Machining Parameters on the 
Fatigue Life of AISI D6 Tool Steel", Journal of Material Processing Technology, Vol.68, pp.27-32, 1997.

5. Ramulu M., Paul G., Pate J., "EDM Surface Effect on the Fatigue Strength of a $15 \mathrm{Vol} \% \mathrm{SiC}_{\mathrm{P}} / \mathrm{Al}$ Metal Matrix Composite Material, Composite Structures, Vol.54, pp.79-86, 2001.

6. Guu Y. H., Hocheng H.," Improvement of Fatigue Life of the Electrical Discharge Machined AISI D2 Tool Steel by TiN Coating “, Materials Science and Engineering A, Vol.318, pp.155-162, 2001.

7. Mamalis A. G., Voaniakos G. C., Vaxevanidis N. M., "Macroscopic and Microscopic Phenomena of Electro-Discharge Machined Steel Surfaces: An Experimental Investigation", J. of Mechanical Working Technology, Vol.15, pp.335 356, 1987.

8. Tai T.Y., Lee H.T., Hsu F.C., "The Influence of Working Parameters and Size Effect on Surface Roughness during EDM Process", Proceedings of $15^{\text {th }}$ International Symposium for Electro-machining (ISEM XV), 2007.

9. Lee H.T., Rehbach W.P., Tai T.Y., Hsu, F.C., "Relationship between Electrode Size and Surface Cracking in the EDM Machining Process", Journal of Materials Science, Vol. 39, No.23, pp. 6981-6986, 2004.

Table1 The surface crack density of SKD11

\begin{tabular}{|c|c|c|c|c|c|}
\hline \multirow{2}{*}{$\mathrm{IL}$} & \multicolumn{5}{|c|}{$\begin{array}{c}\text { The surface crack density of SKD11 } \\
\text { (total length of crack cm / unit area } \mathrm{cm}^{2} \text { ) }\end{array}$} \\
\cline { 2 - 6 } & $4 \mathrm{~A}$ & $6 \mathrm{~A}$ & $8 \mathrm{~A}$ & $12 \mathrm{~A}$ & $16 \mathrm{~A}$ \\
\hline $6 \mu \mathrm{s}(\mathrm{ON})$ & 0.37 & 0.33 & 0.06 & 0.02 & 0.23 \\
\hline $9 \mu \mathrm{s}(\mathrm{ON})$ & 0.51 & 0.405 & 0.13 & 0.08 & 0.05 \\
\hline $12 \mu \mathrm{s}(\mathrm{ON})$ & 1.40 & 0.40 & 0.28 & 0.09 & 0.05 \\
\hline $16 \mu \mathrm{s}(\mathrm{ON})$ & 2.06 & 1.12 & 0.79 & 0.62 & 0.27 \\
\hline
\end{tabular}

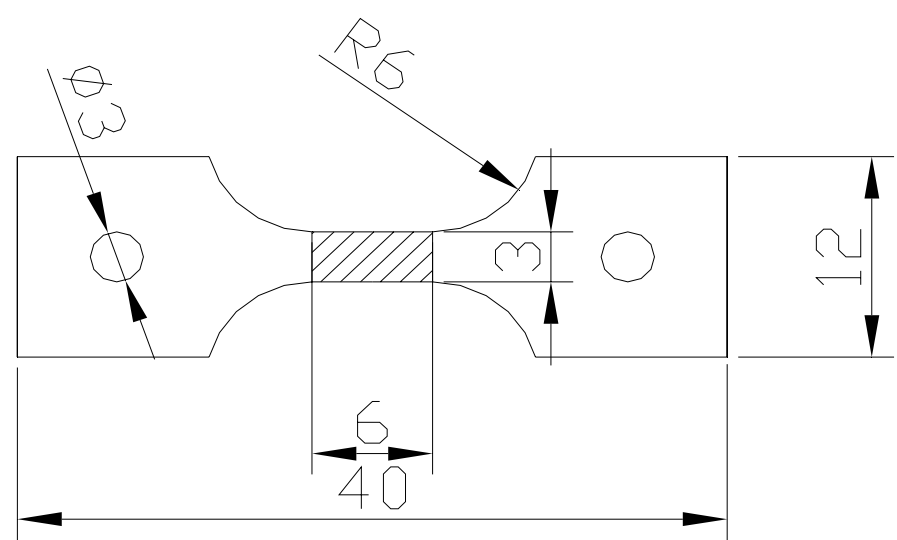

Figure 1 The size of fatigue specimen 


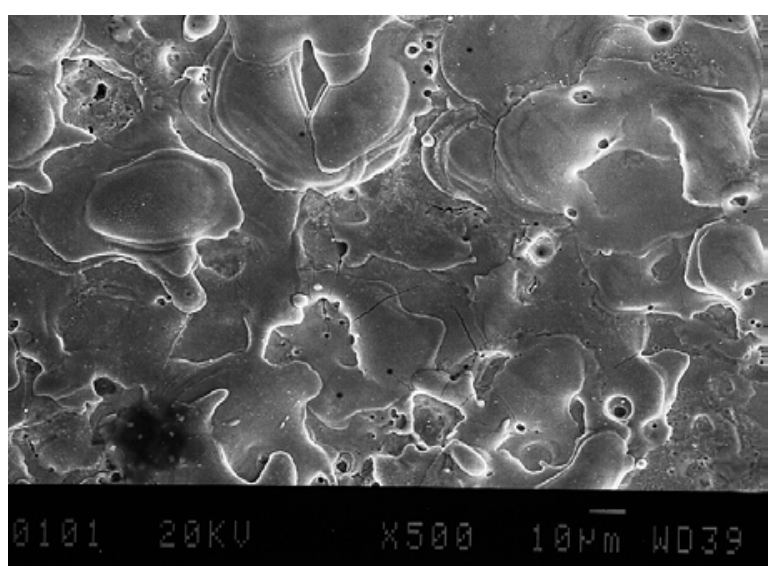

Figure 2 SEM photo shows the surface topography of EDMed surface

(Material: SKD11, pulse current 6A, pulse-on duration $6 \mu \mathrm{s}$ )

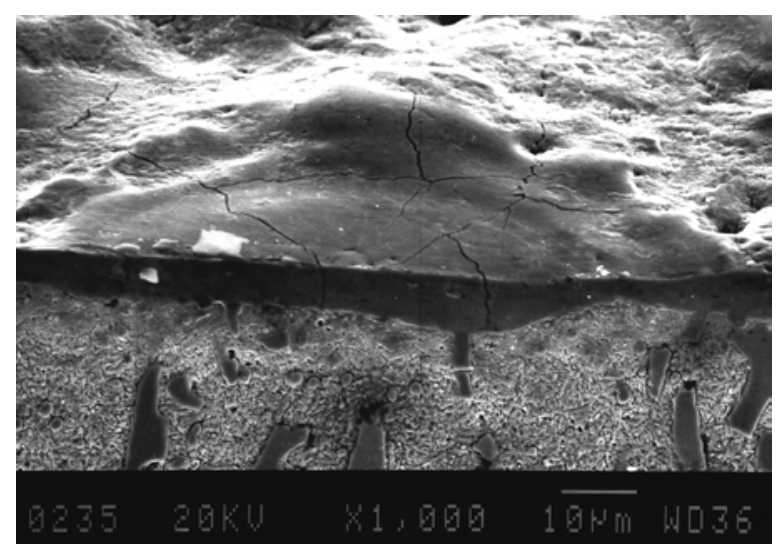

Figure 3 SEM photo shows the recast layer and crack (Material: SKD11, pulse current 4A, pulse-on duration 16 $\mu \mathrm{s}$ )

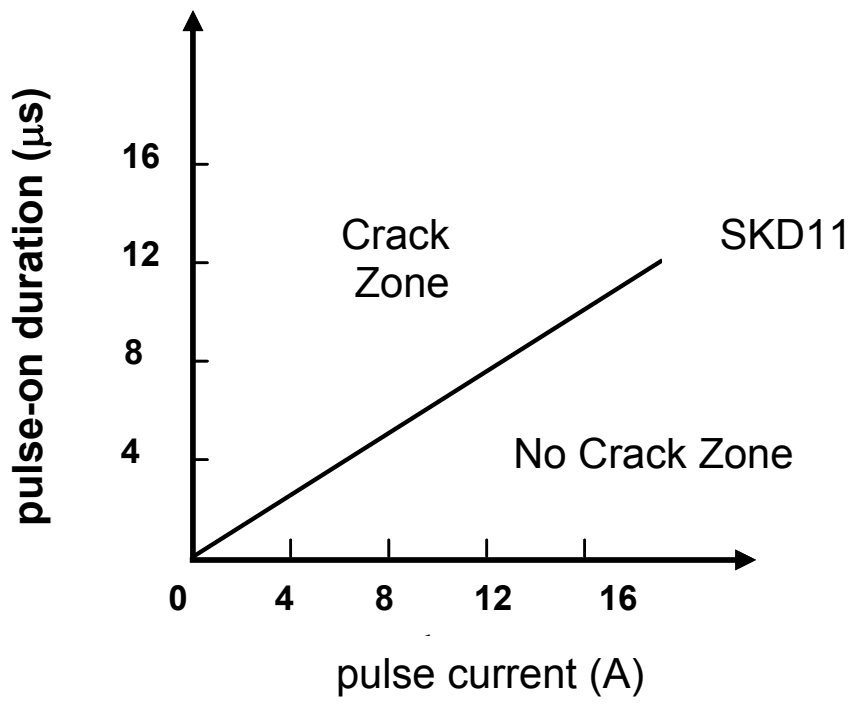

Figure 4 Crack prediction map of SKD11 


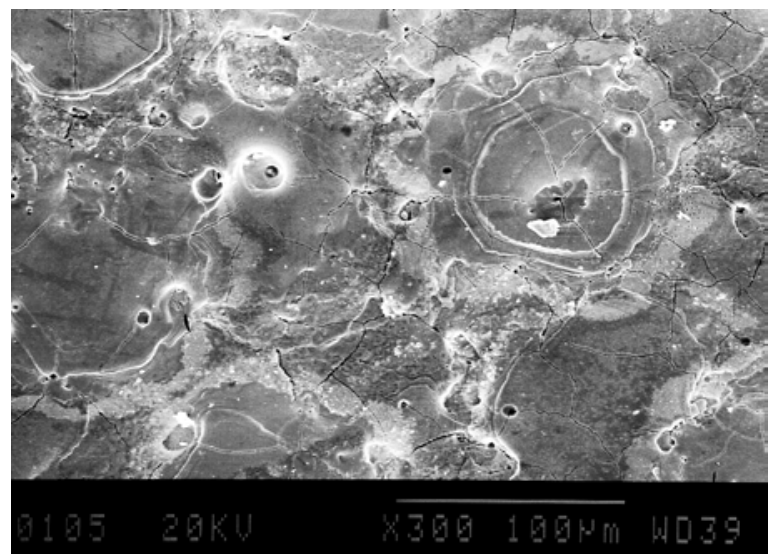

Figure 5 SEM photo shows showing cracks on SKD11 surface machined using pulse current of $4 \mathrm{~A}$ and pulse-on duration of $16 \mu \mathrm{s}$

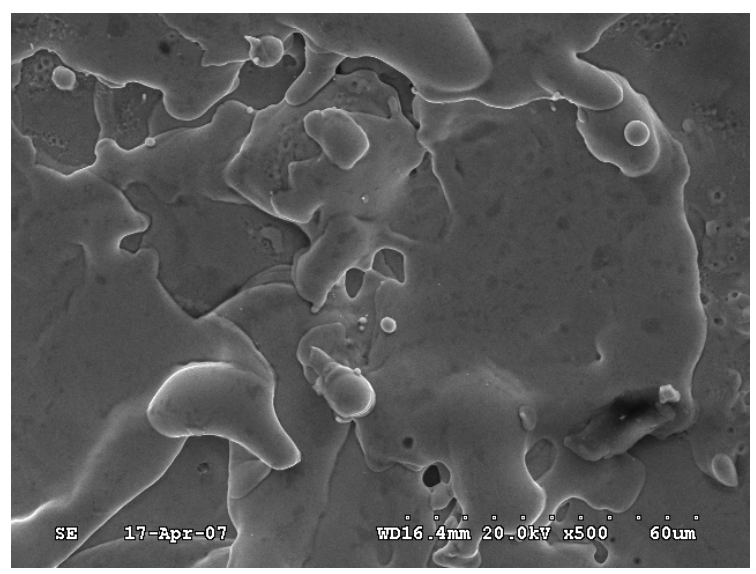

Figure 6 SEM photo shows showing cracks on SKD11 surface machined using pulse current of $16 \mathrm{~A}$ and pulse-on duration of $4 \mu \mathrm{s}$

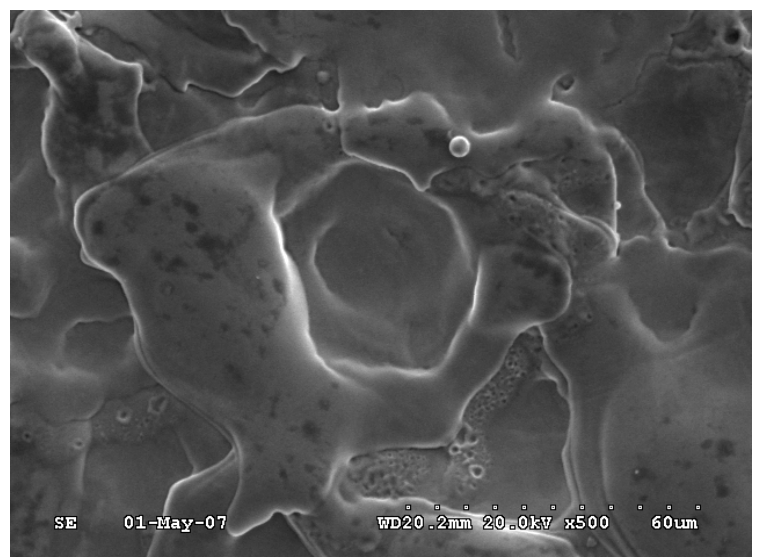

Figure 7 SEM photo shows showing cracks on SKD11 surface machined using pulse current of $32 \mathrm{~A}$ and pulse-on duration of $16 \mu \mathrm{s}$ 


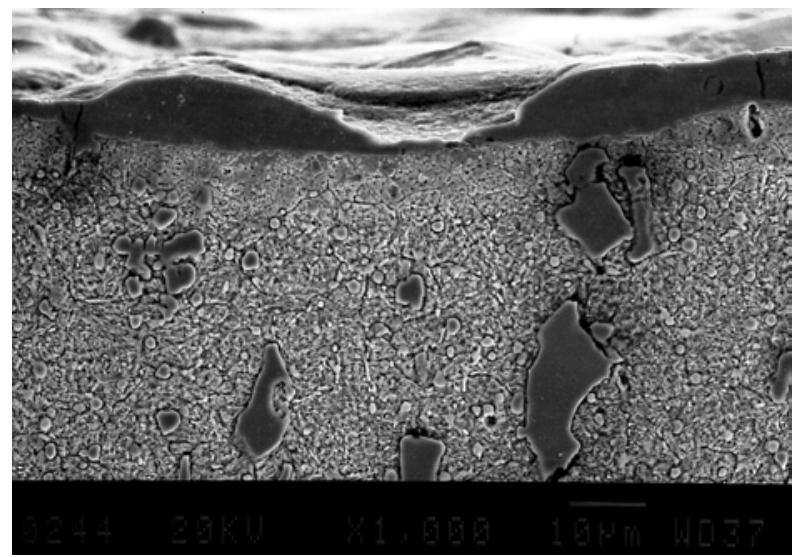

Figure 8 SEM cross-sectional image showing extension of surface crack into SKD11 parent metal in specimen

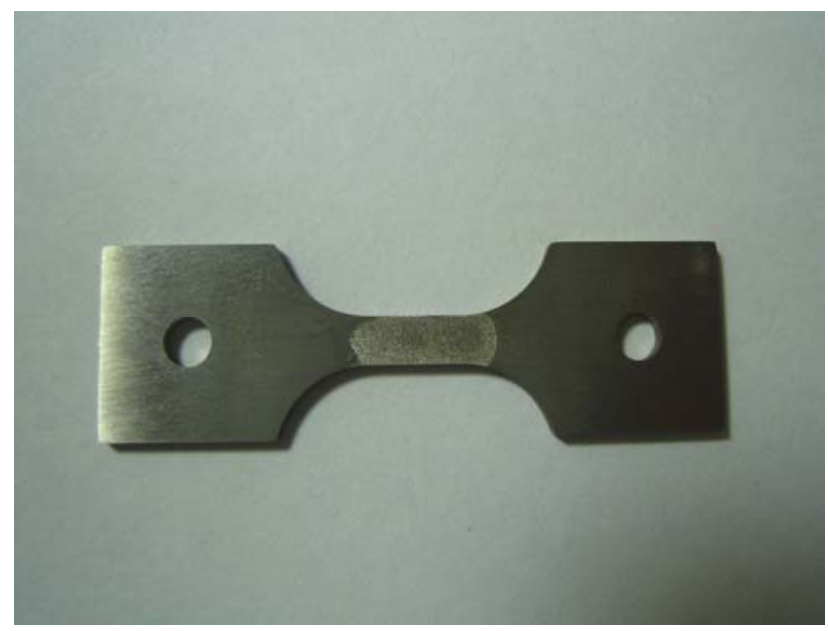

Figure 9 The fatigue specimen which is firstly machined under EDM process

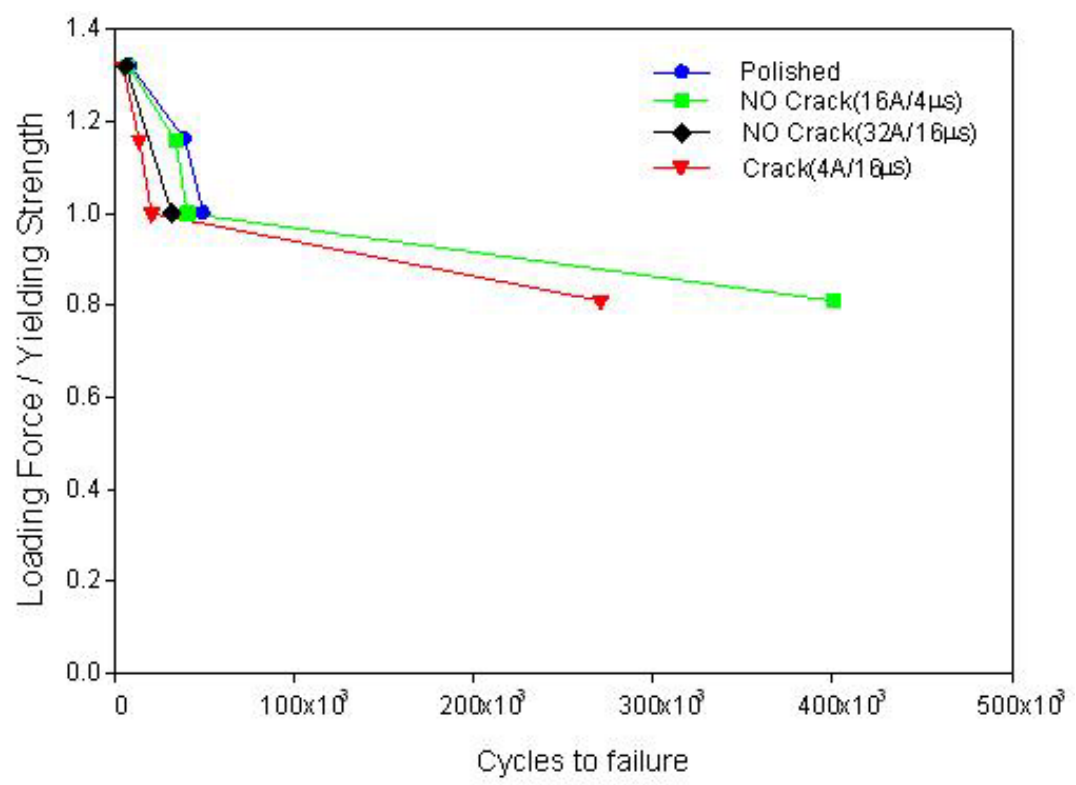

Figure 10 The results of fatigue tests 